\title{
Estrategia metodológica para la enseñanza de estudios sociales en el cuarto grado de básica basada en la animación interactiva
}

\author{
Paúl Santiago Miranda Hernández \\ Egresado de la Maestría en Innovación en Educación. \\ Pontificia Universidad Católica del Ecuador \\ psmh_ec@hotmail.com \\ https://orcid.org/0000-0002-8997-8456
}

\author{
Ricardo Patricio Medina Chicaiza \\ Docente Investigador. Pontificia Universidad Católica del Ecuador \\ pmedina@pucesa.edu.ec \\ https://orcid.org/0000-0002-2736-8214
}

\begin{abstract}
How to cite this paper:
Miranda-Hernández, Paúl Santiago; Medina- Chicaiza, Ricardo Patricio (2020) Estrategia metodológica para la enseñanza de estudios sociales en el cuarto grado de básica basada en la animación interactiva. Revista Encuentros, Universidad Autónoma del Caribe. Vol. 18-01.
\end{abstract}

Doi: 10.15665/encuent.v18i01.2136

Recibido: 30 de septiembre de 2019 / Aceptado: 29 de diciembre de 2019

\section{RESUMEN}

Las ciencias sociales en Ecuador muestran cómo la sociedad vive, en tiempo y espacio. Se elaboró una propuesta metodológica para la enseñanza de los estudios sociales en el 4to grado de Educación General Básica, aplicando la animación interactiva en la Unidad Educativa GRAL. ELOY ALFARO DELGADO, Cantón Ambato. A través de un enfoque cuantitativo y un análisis descriptivo con diseño no experimental, de campo, transeccional y univariable se aplicó un cuestionario de 33 items a una población de 62 alumnos. Los datos indicaron que la formación del docente no es adecuada; la metodología y estrategias de aprendizaje y el ambiente en el aula fueron moderadamente adecuadas. Es necesario capacitar al docente en multimedia. La propuesta da lineamientos para aplicar la animación interactiva.

Palabras clave: animación interactiva, ciencias sociales, enseñanza, aprendizaje

\section{Methodological strategy for teaching social studies in the four- th grade of basic base in interactive animation}

\begin{abstract}
In Ecuador, social sciences show how society lives in time and space. A methodological proposal was developed for the teaching of social studies in the 4th grade of General Basic Education, through the application of interactive animation at the "General Eloy Alfaro Delgado" school located in the Ambato area. Through a quantitative approach and a descriptive analysis, a survey comprising 33 questions was conducted among 62 students. This was done as a non-experimental transversal approach, consisting of one variable. The data indicated that teacher training is not adequate and the methodology and learning strategies and the environment in the classroom were moderately adequate. It is necessary to train the teacher in multimedia. The proposal provides guidelines for applying interactive animation as an educational tool.
\end{abstract}

Keywords: interactive animation, social sciences, teaching, learning 


\title{
Estratégia metodológica para o ensino de estudos sociais na quarta série do ensino fundamental em animação interativa
}

\begin{abstract}
RESUMO
No Equador, as ciências sociais mostram como a sociedade vive no tempo e no espaço. Uma proposta metodológica foi desenvolvida para o ensino de estudos sociais na $4^{\mathrm{a}}$ série do Ensino Básico Geral, através da aplicação de animação interativa na escola "General Eloy Alfaro Delgado", localizada na área de Ambato. Por meio de abordagem quantitativa e análise descritiva, foi realizada uma pesquisa com 33 perguntas entre 62 estudantes. Isso foi feito como uma abordagem transversal não experimental, composta por uma variável. Os dados indicaram que a formação de professores não é adequada e a metodologia e as estratégias de aprendizagem e o ambiente na sala de aula eram moderadamente adequados. É necessário treinar o professor em multimídia. A proposta fornece diretrizes para a aplicação de animação interativa como uma ferramenta educacional.
\end{abstract}

Palavras-chave: animação interativa, ciências sociais, ensino, aprendizagem

\section{Introducción}

Los estudios de las ciencias sociales en la educación básica tienen como objetivo ofrecer a los estudiantes una visión general de la forma cómo la sociedad se desenvuelve considerando su ubicación y desarrollo en el espacio, con una visión más clara de su origen y evolución histórica a través de la enseñanza de la geografía y la historia del mundo, específicamente de la América Latina.

En tal sentido, el proceso de enseñanza de estas asignaturas busca desarrollar destrezas en los alumnos que conlleven a enfrentar otros campos del aprendizaje, así como los desafíos de la innovación y el emprendimiento para así poder identificarse con su pueblo originario, en este caso, con el Ecuador, reconociendo los valores culturales, sociales y libertarios de la democracia y la ciudadanía.Es así como los contenidos de las ciencias sociales en Ecuador van desde el estudio de la identidad propia, personal y familiar del niño e incrementan progresivamente su ámbito temático hasta el conocimiento de los problemas mundiales; afrontando temas básicos relacionados con el entorno y que posteriormente se analizan a través de asignaturas como la historia y la geografía de manera alternada año por año, sin mezclarse. Esto se puede observar en Cívica o Educación para la Democracia; sin embargo, se introduce como una dimensión valorativa los mismos contenidos geográficos e históricos, específicamente como el conocimiento de la realidad actual del Ecuador.
En los primeros años de educación general básica las Ciencias Sociales se convierte en el eslabón fundamental para la comprensión de los temas que serán abordados en los años posteriores. El docente requiere contar con herramientas metodológicas acordes a la realidad cotidiana y cambiante donde conviven los estudiantes y, por tanto, necesita aplicar estrategias metodológicas que incentiven al estudiante a ser más participativo en el salón de clase y a su vez pueda asimilar el contenido impartido en el tema a desarrollar.

De acuerdo con lo planteado por Kajekai (2011,p.1), "en educación, el cumplimiento de los objetivos para el caso de Estudios Sociales, no se logra con el incremento del tiempo que se dedica a la enseñanza, sino esencialmente mediante el incremento del trabajo escolar, en la cual los estudiantes logren desempeñar un papel activo en la clase, donde es necesario el manejo de los recursos didácticos que faciliten la resolución de problemas, la organización de ideas, entre otros, de tal manera que se logre un aprendizaje agradable y profundo”.

En la actualidad, en Ecuador, el docente continúa aplicando metodologías de enseñanza clásicas que traen consigo el hecho que los estudiantes se sientan desmotivados a la hora de adquirir el conocimiento de los contenidos impartidos en las Ciencias Sociales, lo que hace necesario fomentar otros métodos alternativos de enseñanza que permitan al niño sentirse identificado con la temática, generando sus propios conceptos y participar de manera interactiva 
con sus compañeros y el maestro como guía de los contenidos en el salón de clase.

La enseñanza de los estudios sociales en el cuarto grado de educación básica general requiere de la incorporación de estrategias acordes con el avance tecnológico que poseen los estudiantes; los alumnos a este nivel ya cuentan con una comprensión lectora y de resolución de problemas intermedio-avanzado que propician el ambiente ideal para motivarlos a utilizar otras herramientas de aprendizaje.

En virtud de ello se propuso el uso de la animación interactiva como metodología de saberes, con el propósito de generar un cambio en el aprendizaje de los estudiantes, fomentando su motivación y participación en el aula de clase, propiciando acciones diarias más amenas e incrementando su interés en la asignatura. De esta manera su aplicación se convierte en una estrategia innovadora acorde con el contexto educativo global y sirve como método de enseñanza para ser utilizado en otras disciplinas de la educación básica general en el Ecuador.

Por lo antes expuesto, la propuesta metodológica fue aplicada en la Unidad Educativa GRAL. ELOY ALFARO DELGADO, fundada el 8 de octubre de 2012, mediante Resolución No. 397-CZE3-2012 y ubicada en la Provincia de Tungurahua, Cantón Ambato, específicamente a los alumnos del cuarto grado de educación general básica, en la asignatura de ciencias sociales.

La interrogante inicial de esta investigación atendió a la siguiente hipótesis de trabajo: ¿La animación interactiva como estrategia metodológica mejorará la enseñanza de las Ciencias Sociales en el cuarto grado de Educación Básica General? Para dar respuesta a la misma se formuló el objetivo general: Elaborar una propuesta metodológica de enseñanza de Estudios Sociales en el cuarto grado de Educación General Básica aplicando la animación interactiva.

\section{Fundamento teórico}

La construcción de los fundamentos teóricos de la investigación conllevó a realizar una revisión documental y bibliográfica acerca del tema objeto de estudio; es así como se conoció el trabajo realizado por Bolaño García (2017) titulado Uso de Herramientas Multimedia
Interactivas en educación preescolar, la cual sirvió para identificar los tipos de herramientas multimedia Interactivas usadas por los docentes para la enseñanza en educación preescolar de las Instituciones Educativas Distritales (IED) pertenecientes a la comuna 6 del Distrito Turístico Cultural Histórico de Santa Marta Colombia. A través del análisis descriptivo y la aplicación de un instrumento a 38 docentes de preescolar de las IED, los hallazgos indicaron que los docentes hacen poco uso de simuladores, los tutoriales y ejercitadores, los cuales son tipos de herramientas multimedia interactivas que se esperaban fueran manejadas por la población en forma eficiente y efectiva; develando la necesidad de su inclusión en las actividades cotidianas, implicando beneficios tanto para el aprendizaje de los niños de edad preescolar como en la práctica del docente.

Por su parte, García-Hernández (2014) diseñó una Estrategia metodológica para la elaboración y utilización de objetos de aprendizaje interactivo y experimental en el proceso de enseñanza aprendizaje de la Matemática Discreta en la Universidad de las Ciencias de la Informática UCI, Cuba, a través del enfoque histórico cultural de Vigotski y los resultados revelaron insuficiente aprovechamiento de las TIC por parte de los estudiantes que no se sienten motivados por el aprendizaje de la asignatura, lo que fortaleció la implementación del objeto de la investigación.

Con referencia al uso de la Animación interactiva como metodología didáctica, Horno López (2011) propuso una nueva metodología docente en la que se utiliza la animación como herramienta didáctica potenciadora del aprendizaje. Mediante el uso de técnicas sencillas de animación se lleva a cabo una experiencia didáctica que pone de manifiesto que el uso de la animación interactiva favorece una mayor implicación de los estudiantes y un aprendizaje más dinámico y fluido. Concluyó que el uso de dibujos animados constituye un elemento motivador para la participación del alumnado como material interactivo y didáctico que fomenta la cooperación entre los alumnos; complementar las enseñanzas del profesor con la animación favorece la comprensión y mejora del aprendizaje, el análisis de dibujos animados propicia la reflexión crítica y evidencia una mejora en la capacidad perceptiva de los alumnos, potenciando la sociabilidad entre ellos y el trabajo en grupo. 


\section{La Animación Interactiva}

Según Gene Deitch, citado por Rodríguez-Fernández (2015, p.52)" animación es el registro de una acción, en fases individuales e imaginadas de una forma tal que, si se reproduce este registro a una velocidad determinada y constante, siempre y cuando esta velocidad exceda la persistencia de la imagen en el ojo, se produce la ilusión de movimiento en el observador". Por su parte, Taylor (2000, p.7) afirma que "la animación es la creación de una ilusión de movimientos a través de la unión de una secuencia de imágenes".

De las afirmaciones expuestas resalta la cualidad de movimiento, velocidad, secuencia de imágenes, elementos que requieren de interacción humana o digital para su exposición.

A manera de ilustración cabe mencionar la existencia de los 12 principios de la animación desarrollados por estudios Disney alrededor de los años 30 que tal como lo menciona Eguaras (2015, p.13) "no existe una fecha de redacción ni de autoría pero que ejemplarizan el nacimiento de esta acción hoy en día”. Según Thomas y Jonhston(1981)" la recopilación de estos principios se convirtió en el fundamento del trabajo de animación de esta empresa".

Los mismos incluyen aspectos de las leyes de la física, de la personalidad y procesos técnicos de animación propiamente dicha. Según Eguaras (2015, p.15) "muchos de ellos se desarrollaron simultáneamente, se aislaron y se definieron así: estirar y encoger (squash and strech), anticipación (anticipation), puesta en escena (staging), acción directa y pose a pose (straight ahead action and pose to pose), acción continuada y superpuesta (Follow throught and overlapping action), aceleración y desaceleración de entradas y salidas (slow in and slow out), arcos (Arcs), acción secundaria (secondary action), cadencia (timing), hipérbole (exaggeration), dibujo sólido (solid drawing) y personalidad (appeal)”.

La innovación realizada por estudios Disney sirvió de base para construir los elementos diferenciadores del proceso de animación. Sin embargo, para el estudio que nos ocupa cabe mencionar que, aun cuando se han encontrado referencias teóricas de los componentes de los términos: animación e interactiva, no se ha ubicado un concepto construido teóricamente que unifique el contenido de ambas definiciones para lo cual pudiera asumirse por analogía la definición de animación por ordenador realizada por la Escuela de Informática de la Universidad de Murcia (2005, p.7) concebida como la "generación, almacenamiento y presentación de imágenes que en sucesión rápida producen sensación de movimiento."

La conjunción del elemento de animación con el proceso de interactividad permite identificar entonces el componente teórico de la definición de animación interactiva como una estrategia de enseñanza.

\section{Las tecnologías de la información y la comunicación (TIC'S) y la enseñanza}

Hablar de las tecnologías de la información y la comunicación (TIC's) en la enseñanza, en el aprendizaje, en la formación, requiere necesariamente ubicar cuáles son los medios o formas y recursos que se emplearán para realizar las acciones de docencia y los contenidos que se estudiarán. De ahí que sea fundamental elegirlos para aseguramos de la actividad mental que estimula, la facilidad que tenga para transmitir información, la capacidad para conectar con las características cognitivas de los alumnos y situarnos en un punto de partida eficaz.

Ahora bien, de acuerdo con lo planteado por la DECLARACION MUNDIAL SOBRE LA EDUCACION SUPERIOR EN EL SIGLO XXI: VISION Y ACCION, artículo 12, "los rápidos progresos de las tecnologías de la información y la comunicación modifican la forma de elaboración, adquisición y transmisión de conocimientos". (UNESCO, 1998, s/p). La educación debe hacer frente a los retos que suponen las nuevas oportunidades que abren las tecnologías, que mejoran la manera de producir, organizar, difundir, controlar el saber y acceder al conocimiento. Debe garantizarse un acceso equitativo a estas tecnologías en todos los niveles de los sistemas de enseñanza.

En este sentido, tal como afirma Laborí (s/f), las TIC'S suponen en ese ámbito una nueva forma de organizar, representar y codificar la realidad, son además instrumentos valiosos para lograr un elevado grado de aplicación de los conocimientos adquiridos. El profesional de la enseñanza no puede permanecer ajeno a esta situación, por lo que debe hacer un esfuerzo en lo que a la actualización tecnológica se refiere una vez superada la posible intimidación que la tecnología puede 
suponer. Las tecnologías del aprendizaje representan una de las fuerzas renovadoras en los sistemas de aprendizaje y constituyen un elemento clave para el desarrollo de la educación y la formación. Consecuentemente la investigación sobre la mejor manera de fortalecer la tecnología para propósitos de aprendizaje, tendrá una fuerte influencia en la construcción de las futuras formas de aprendizaje. En este sentido es preciso pensar, fundamentar y desarrollar un determinado modo de relación entre las nuevas tecnologías y la educación que se debe calificar de integrador.

En el proceso de enseñanza aprendizaje que aquí se analiza a partir del uso de la animación interactiva, se hace necesario contar con métodos que posibiliten el manejo interactivo de los recursos. Así Quinquer (2004, p.5) afirma que los diversos métodos interactivos tienen muchos elementos en común y no siempre resulta fácil delimitar la frontera que los diferencia. El alumnado se convierte en el centro de la actividad y el profesorado ayuda y facilita el proceso. Asimismo, los métodos interactivos se optimizan si en su puesta en práctica se fomenta la cooperación, puesto que la interacción que entonces se produce entre los mismos estudiantes y entre estos y el profesorado facilita el aprendizaje. Para ello se requiere que el alumno:

- Utilice estrategias para procesar información procedente de exposiciones orales, de textos escritos, de material cartográfico, icónico o estadístico.

- Organice su trabajo, aplicando los principales pasos del método científico.

- Presente adecuadamente los resultados mediante la elaboración de textos descriptivos, explicativos y argumentativos, elaborando y/o comentando mapas o croquis, seleccionando y comentando fotografías, utilizando tablas estadísticas y gráficas y presentando ordenadamente una exposición verbal.

El método de casos, el aprendizaje basado en problemas, la realización de investigaciones, de simulaciones, las exposiciones son algunas formas de interacción del proceso de enseñanza donde al alumno se convierte en el eje principal de la acción que se refuerza con el trabajo en equipo de tipo colaborativo y cooperativo.

Refiere el mismo autor, Quinquer (2004, p.7) que los métodos interactivos sirven para:
1. La aplicabilidad y significatividad de los contenidos es más evidente porque se presentan de manera contextualizada, a menudo se trata de problemas reales o situaciones prácticas que implican el dominio de destrezas similares a las que debe manejar un profesional de la geografía, de la historia o de otras ciencias sociales.

2. Se trabajan habilidades de pensamiento crítico: generar ideas, solucionar problemas, elaborar hipótesis, verificarlas, de tomar decisiones etc.

3. Se desarrollan habilidades interpersonales y de trabajo en equipo, de comunicación como buscar información, seleccionarla, comunicarla por escrito y oralmente, interrogar, argumentar, utilizar lenguaje especializado, etc.

4. El clima del aula suele ser participativo, dinámico. Evidentemente, todo ello requiere: un diseño adecuado, unos equipos o grupos de trabajo que funcionen bien, la optimización del tiempo disponible, la coherencia desde la perspectiva de los contenidos que se imparten y una gestión del aula eficiente.

Ahora bien, de estos diferentes métodos interactivos de enseñanza es necesario recalcar la utilización de la multimedia, objeto de esta investigación.

\section{El uso de la multimedia en el proceso de enseñanza-aprendizaje}

Incorporar herramientas tecnológicas en el proceso de enseñanza- aprendizaje ha estado en boga desde hace varios años y las mismas se van modificando rápidamente ejerciendo un rol importante en la formación de niños, adolescentes y adultos. Sin embargo, cabe preguntarse ¿qué es la multimedia? Según, Marqués (1999) citado por Belloch (s/f), la conciben como "un programa informático que introduce medios o elementos textuales y audiovisuales, en un mismo entorno, interactuando entre sí para facilitar determinados aprendizajes”. Para algunos autores constituyen herramientas o materiales de aprendizaje (Sangra, Guardia, Mas y Girona, 2005, Bolaños, 2017), para otros como Tizón (2008), son "medios digitales ya sean tanto de texto, gráficos, hipertexto, animación, voz y vídeo”.

Para esta investigación se asume la definición de multimedia ofrecida por Hoffstetter (2001) quien afirma 
que es el "uso del ordenador para presentar y combinar: texto, gráficos, audio y vídeo con enlaces que permitan al usuario navegar, interactuar, crear y comunicarse".

La amplitud de comunicación que ofrece la multimedia es un elemento primordial para apoyar la enseñanza y el aprendizaje en el aula, ofrece al alumno la posibilidad de interactuar con la realidad en el tiempo presente y fortalece el intercambio de información actualizada, veraz y oportuna.

Afirma Bolaño García (2017) que países como España utilizan las herramientas multimedia interactivas en la educación preescolar con la finalidad de proporcionar experiencias innovadoras y preparar a los niños a que manejen un lenguaje tecnológico desde hace más de diez años. A nivel mundial existen prácticas exitosas a través del uso de este recurso, lo que puede reforzar la hipótesis aquí formulada.

\section{Metodología}

La investigación se realizó desde un enfoque cuantitativo y se abordó a partir del análisis descriptivo que según Hernández et al (2014, p.92) busca especificar las propiedades, las características y los perfiles de personas, grupos, comunidades, procesos, objetos o cualquier otro fenómeno que se someta a un análisis. En razón de ello el diseño del estudio fue de tipo no experimental, de campo, transeccional y univariable. La recolección de los datos se efectuó en una sola oportunidad y se aplicó como técnica un cuestionario tipo encuesta a los estudiantes del cuarto grado de Educación Básica General sobre los factores que afectan el proceso de enseñanza de Estudios Sociales.

La población, definida por Ander Egg (2011, p.106) como el "conjunto de elementos de los que se quiere conocer o investigar algunas de sus características" fue constituida por un total de 1344 estudiantes, de los cuales 62 alumnos pertenecieron al cuarto grado de Educación Básica General: 31 en el turno matutino y 31 en el turno vespertino, quienes fueron el objeto de estudio.

Por cuanto la población estudiada fue finita (62 estudiantes del cuarto grado de educación básica general) no fue necesario extraer una muestra ya que se pudo acceder a todos los integrantes de la misma y de esta manera trabajar con la totalidad de los sujetos. Según Arias (2012, p.82) una población finita es la agrupación de la que se conoce la cantidad de unidades que la integra.

De igual forma, para recolectar la información se empleó un instrumento de medición constituido por treinta y tres (33) items con una escala de tipo Likert de tres (3) alternativas de respuesta (siempre, a veces, nunca) construido de acuerdo con los indicadores de la variable: enseñanza de las ciencias sociales y fundamentadas en el sistema teórico. El mismo fue sometido a la validación a través de juicio de seis (6) expertos en el área de informática y educación. Según Hernández et al (2014, p. 200) la confiabilidad de un instrumento de medición se refiere al grado en que su aplicación repetida al mismo individuo u objeto produce resultados iguales; de acuerdo con esta definición se aplicó una prueba piloto a una población diferente con características semejantes al objeto de estudio. Los resultados obtenidos de la prueba, aportados por el instrumento, permitieron determinar su confiabilidad a través del coeficiente Alpha de Cronbach, el cual dio como valor 0,903 , indicando que el mismo es altamente confiable.

Para el análisis de los resultados de los datos obtenidos del cuestionario aplicado se utilizó el siguiente baremo:

1,00 a 1,66: inadecuado;

1,67 a 2,33: moderadamente adecuado;

2,34 a 3,00: adecuado.

\section{Análisis de resultados}

A través del uso y aplicación de la estadística descriptiva e inferencial, tales como distribuciones de frecuencia, medidas de tendencia central, de dispersión y prueba de Friedman se analizaron los resultados utilizando el paquete estadístico SPSS, versión 20, de acuerdo con la variable: propuesta metodológica de enseñanza de Estudios Sociales; la dimensión de la variable: factores que afectan el proceso de enseñanza de Estudios Sociales y los siguientes indicadores: ambiente en el aula, metodología del aprendizaje, estrategias de enseñanza y formación docente.

1. El ambiente en el aula: El análisis estadístico indicó que en la respuesta asociada a este indicador 
el 41,9\% del total de los encuestados se ubicó hacia la opción: a veces, mientras que el 35,5\% respondió: siempre y el 22,6\% seleccionó la opción: nunca; tal como se refleja en la Tabla No. 1 y el gráfico No. 1, respectivamente. El valor de la media aritmética del indicador fue de 2,1290, con una desviación estándar de 0,75 (Tabla No. 2), ubicándose en la categoría del baremo: Moderadamente adecuado.

Tabla No. 1. Indicador: El ambiente en el aula

\begin{tabular}{lcccc}
\hline Válido & Frecuencia & Por ciento & \% Válido & \% Acumulado \\
\hline Nunca & 14 & 22,6 & 22,6 & 22,6 \\
A veces & 26 & 41,9 & 41,9 & 64,5 \\
Siempre & 22 & 35,5 & 35,5 & 100,0 \\
Total & 62 & 100,0 & 100,0 & \\
\hline
\end{tabular}

Gráfico No. 1. Indicador: El Ambiente en el Aula

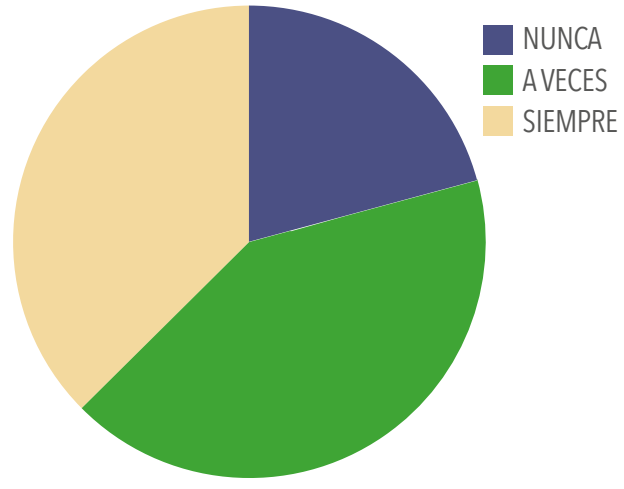

Fuente: Elaboración propia (2019)

Tabla No. 2. Estadística descriptiva Indicador. El ambiente en el aula

\begin{tabular}{cc}
\hline Válido & 62 \\
\hline Perdido & 0 \\
Media & 2,1290 \\
Desviación estándar &, 75713 \\
\hline
\end{tabular}

Fuente: Elaboración propia (2019)

La lectura de estos datos refuerza el sustento teórico que explica la importancia de contar con espacios adecuados para desarrollar el proceso de enseñanzaaprendizaje y que, en este caso, los alumnos consideran que el mismo medianamente sirve para cumplir sus actividades académicas.
2. Metodología del aprendizaje: Con referencia a este indicador, del análisis de los datos se puede inferir que el 43,6\% de los alumnos contestó la opción: a veces y el $41,9 \%$ respondió: nunca; mientras que el 14,5\% tendió a la opción: siempre. (Tabla No. 3 y Gráfico No. 2). El promedio aritmético arrojó un valor de 1,7258, con una desviación estándar de 0,70 (Tabla No. 4), lo cual permite inferir que la metodología de aprendizaje aplicada por el docente para la enseñanza de las ciencias sociales en el 4to grado de Educación General Básica es moderadamente adecuado.

\begin{tabular}{lcccc}
\multicolumn{5}{c}{ Tabla No. 3. Indicador: Metodología del aprendizaje } \\
\hline Válido & Frecuencia & Por ciento & \% Válido & \% Acumulado \\
\hline Nunca & 26 & 41,9 & 41,9 & 41,9 \\
A veces & 27 & 43,6 & 43,6 & 85,5 \\
Siempre & 9 & 14,5 & 14,5 & 100,0 \\
Total & 62 & 100,0 & 100,0 & \\
\hline \multicolumn{5}{c}{ Fuente: Elaboración propia (2019). }
\end{tabular}

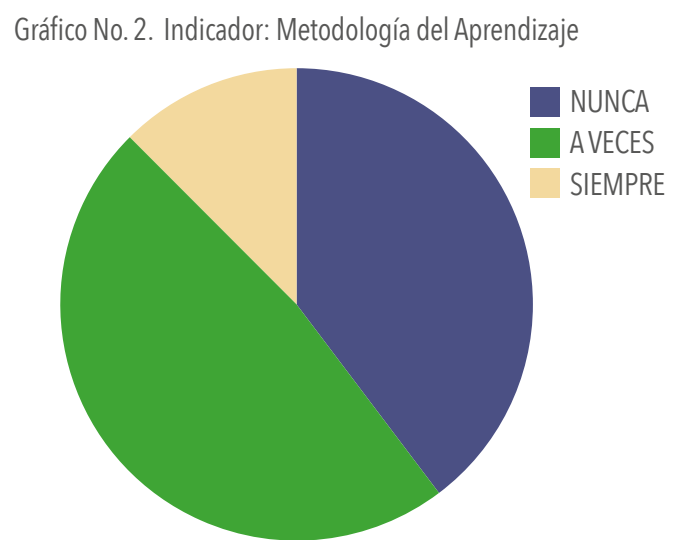

Fuente: Elaboración propia (2019)

Tabla No. 4. Estadística descriptiva Indicador. Metodología del aprendizaje

\begin{tabular}{cc}
\hline Válido & Perdido \\
\hline 62 & 0 \\
Media & 1,7258 \\
Desviación estándar &, 70523 \\
\hline
\end{tabular}

Una adecuada metodología de aprendizaje constituye una herramienta fundamental en el proceso educativo. El docente debe contar con acciones formativas 
adecuadas que incentiven a la participación del alumno, a mantener un ambiente motivador, dinámico y reflexivo que permita fomentar la discusión y el análisis entre los estudiantes. El análisis de los datos aquí obtenidos refiere a la necesidad de reforzar el uso de un método de enseñanza adecuado a los contenidos de la asignatura.

3. Estrategias de Aprendizaje. El resultado del análisis de este indicador indicó que el 69,4\%de los alumnos respondió la opción: a veces, mientras que el 30,6\% contestó: nunca (Tabla No. 5 y Gráfico No. 3). El valor promedio se ubicó en 1,6935, con una desviación estándar de 0,46 (Tabla No. 6), lo cual permite inferir que las estrategias de aprendizaje son moderadamente adecuadas.

\begin{tabular}{lcccc}
\multicolumn{5}{c}{ Tabla No. 5. Indicador: Estrategias de Aprendizaje } \\
\hline Válido & Frecuencia & Por ciento & \% Válido & \% Acumulado \\
\hline Nunca & 19 & 30,6 & 30,6 & 30,6 \\
A veces & 43 & 69,4 & 69,4 & 100,0 \\
Total & 62 & 100,0 & 100,0 & \\
\hline \multicolumn{5}{c}{ Fuente: Elaboración propia (2019). }
\end{tabular}

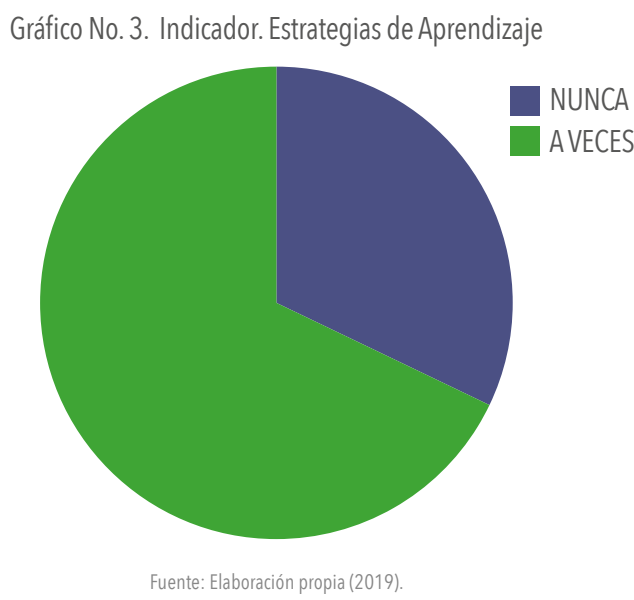

Tabla No. 6. Estadística descriptiva Indicador. Estrategias de Aprendizaje

\begin{tabular}{rc}
\hline Válido & 62 \\
\hline Perdido & 0 \\
Media & 1,6935 \\
Desviación estándar &, 46478 \\
\hline
\end{tabular}

Fuente: Elaboración propia (2019).
De los datos del cuestionario aplicado relacionados con este indicador, se deduce la necesidad de diseñar e implementar estrategias de aprendizaje acordes con la metodología de enseñanza de las ciencias sociales que permitan profundizar en el conocimiento de la asignatura y que, a su vez, motiven al estudiante a aprender y analizar los principales conceptos, a través del uso de técnicas innovadoras e interactivas.

4. Formación Docente. Con referencia al análisis de este indicador, se tiene que el 58,1\% de los estudiantes seleccionó la opción: a veces y el 41,9\% se ubicó en la opción: nunca (Tabla No. 7 y Gráfico No. 4). El valor promedio fue de 1,5806, con una desviación estándar de 0,49 (Tabla No. 8), lo que indica que la formación docente es inadecuada.

\begin{tabular}{lcccc}
\multicolumn{5}{c}{ Tabla No. 7. Indicador. Formación Docente } \\
\hline Válido & Frecuencia & Por ciento & \% Válido & \% Acumulado \\
\hline Nunca & 26 & 41,9 & 41,9 & 41,9 \\
A veces & 36 & 58,1 & 58,1 & 100,0 \\
Total & 62 & 100,0 & 100,0 & \\
\hline \multicolumn{5}{c}{ Fuente: Elaboración propia (2019). }
\end{tabular}

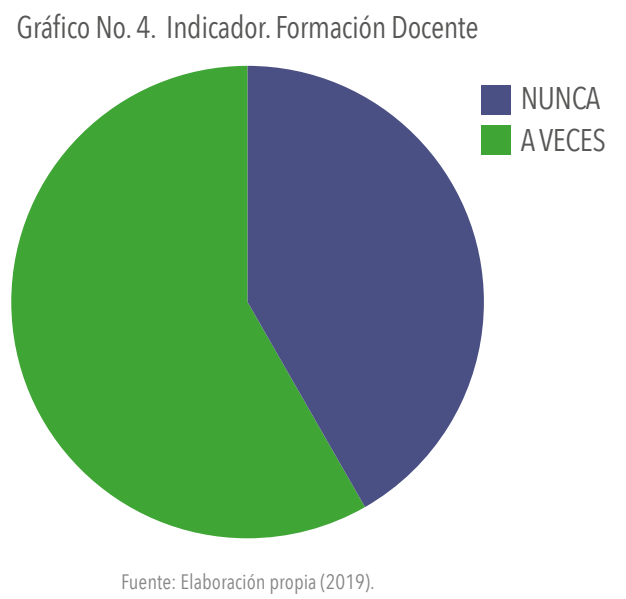

Tabla No. 8. Estadística descriptiva Indicador. Formación Docente

\begin{tabular}{rc}
\hline Válido & 62 \\
\hline Perdido & 0 \\
Media & 1,5806 \\
Desviación estándar &, 49748 \\
\hline
\end{tabular}

Fuente: Elaboración propia (2019). 
El resultado de inadecuada formación del docente en la enseñanza de las ciencias sociales en el 4to grado de Educación General Básica, aplicando la animación interactiva, justifica la intención de esta investigación al elaborar una propuesta metodológica. La formación del docente es clave en el proceso de enseñanza-aprendizaje; de su educación en la instrucción de esta asignatura de forma motivadora, inclusiva, dinámica y con conocimientos para el uso de herramientas multimedia depende, en gran medida, el estudio y aplicación de los saberes. La capacitación del docente en animación interactiva es necesaria para lograr resultados óptimos en la evaluación del estudiante.

Ahora bien, como complemento del análisis estadístico realizado a los datos, se aplicó la prueba de Friedman para conocer el comportamiento de los factores de la enseñanza de estudios sociales, de acuerdo como lo indican los rangos promedio, a saber: menor rango: formación docente $(2,20)$; seguido por estrategias de aprendizaje $(2,37)$; luego metodología del aprendizaje $(2,39)$ y el mayor rango correspondiente al ambiente en el aula (3,04), tal como se aprecia en la tabla No. 9. La mencionada prueba dio como resultado que existen diferencias significativas entre los mismos (Tabla No. 10); lo que indica que es necesario mejorar la formación del docente haciéndolo capaz de diseñar estrategias de aprendizaje adecuadas con el uso de la animación interactiva, que permitan lograr la implementación de una metodología apropiada para la enseñanza de esta asignatura, en un ambiente de aula propicio y cónsono con el proceso educativo.

Tabla No. 9. Rangos Promedios

\begin{tabular}{cc}
\hline & Rangos Promedio \\
\hline El ambiente en el aula & 3,04 \\
Metodología del aprendizaje & 2,39 \\
Estrategias de Aprendizaje & 2,37 \\
Formación Docente & 2,20 \\
\hline
\end{tabular}

Fuente: Elaboración propia (2019).

Tabla No. 10. Prueba Estadística de Friedman

\begin{tabular}{cc}
\hline $\mathrm{N}$ & 62 \\
\hline Chi-Square & 27,435 \\
$\mathrm{df}$ & 3 \\
Asymp. Sig. &, 000 \\
\hline
\end{tabular}

Fuente: Elaboración propia (2019).
Propuesta metodológica de enseñanza de Estudios Sociales en el cuarto grado de Educación General Básica aplicando la animación interactiva.

El Ministerio de Educación de la República de Ecuador (ME), según acuerdo Nro. MINEDUC-ME-201600020-A acordó expedir los currículos de educación general básica para los subniveles de preparatoria, elemental, media y superior; y, el currículo de nivel de bachillerato general unificado, con sus respectivas cargas horarias, cuya reforma fue realizada en documento de acuerdo Nro. MINEDUC-MINEDUC-2018-00089-A. El mencionado currículo comienza a tener vigencia en las escuelas ecuatorianas a partir del 2016.

El currículo de Ciencias Sociales de los niveles de educación obligatoria, de acuerdo con el documento elaborado por el ME (2016) es un instrumento:

diseñado como una estructura coherente $y$ lógicamente cohesionada...se implementa por medio del tratamiento de las asignaturas de Estudios Sociales (en la Educación General Básica) y de Historia, Educación para la Ciudadanía y Filosofía (en el Bachillerato General Unificado), hermanando las categorías de tiempo, espacio, sociedad y pensamiento, sus mutuas relaciones e implicaciones, signadas a su vez por otras tan esenciales como trabajo, cultura, identidad, diversidad, interculturalidad, ética, estética, política, etc., y apuntando a los valores de justicia, innovación y solidaridad, como horizontes teleológicos del quehacer educativo. (ME, 2016, p.148)

El citado documento persigue como objetivo general: determinar los orígenes del universo, el sistema solar, la tierra, la vida y el ser humano, sus características y relaciones históricas y geográficas, para comprender y valorar la vida en todas sus manifestaciones. (ME, 2016, p.180). Se indica aquí el contenido fundamental de la asignatura.

Ahora bien, el máximo organismo rector en política educativa establece las orientaciones metodológicas necesarias para la aplicación del currículo. En tal sentido, indica en el literal 10 del mencionado documento que:

Las instituciones educativas desarrollarán métodos que tengan en cuenta los diferentes ritmos y estilos 
de aprendizaje de los estudiantes, favoreciendo su capacidad de aprender por sí mismos y promoviendo el trabajo en equipo. Se fomentará una metodología centrada en la actividad y participación de los estudiantes que favorezca el pensamiento racional y crítico, el trabajo individual y cooperativo del alumnado en el aula, que conlleve la lectura y la investigación, así como las diferentes posibilidades de expresión. En el caso de la Educación General Básica, especialmente en sus primeros tres subniveles, se integrarán en todas las áreas referencias a la vida cotidiana y al entorno inmediato de los estudiantes. El objeto central de la práctica educativa es que el estudiante alcance el máximo desarrollo de sus capacidades y no el de adquirir de forma aislada las destrezas con criterios de desempeño propuestas en cada una de las áreas, ya que estas son un elemento del currículo que sirve de instrumento para facilitar el aprendizaje (ME, 2016, p.7)

Tomando como base la política educativa nacional, la propuesta tiene como objetivo el siguiente:

Objetivo: Enseñar el contenido de las ciencias sociales en el cuarto grado de Educación General Básica aplicando la animación interactiva como estrategia didáctica.

Se asume la definición teórica de estrategia didáctica afirmada por Tebar (2003, p.7) como procedimientos que el agente de enseñanza utiliza en forma reflexiva y flexible para promover el logro de aprendizajes significativos en los estudiantes.

Ahora bien, una vez definidos por el Ministerio de Educación del Ecuador los contenidos de las ciencias sociales para el cuarto grado de Educación General Básica, fundamento de esta propuesta, se considera importante reforzar la necesidad imperiosa de contar con docentes formados en el uso y aplicación de herramientas digitales y multimedia, por cuanto estas facilitarán la interacción entre alumno y profesor, propiciando un ambiente de aula adecuado para potenciar el proceso educativo. Para ello se identifican tres momentos fundamentales del acontecer cotidiano de la enseñanza, a saber: antes, durante y después de la clase expositiva.

1. Previo a la clase: Analizar el contenido a explicar antes de la clase expositiva requiere un proceso de búsqueda documental que debe realizar el docente. En esta revisión bibliográfica encontrará los elementos necesarios y fundamentales de los conceptos a enseñar y del objetivo de aprendizaje. Conocer la temática le permitirá al docente identificar los recursos de multimedia requeridos para realizar su explicación y la mejor forma de aclarar dudas, en consonancia con la rúbrica de evaluación. El profesor, una vez identificado el tema a tratar, deberá elaborar un diálogo que le permita interconectar cada aspecto del contenido y facilitar la explicación a los alumnos a través del uso de la animación interactiva.

2. Durante la clase: Este momento es fundamental. El profesor se convierte en el sujeto-actor del arte de comunicar. El docente deberá utilizar un lenguaje inclusivo y motivador que despierte interés en el alumno por conocer el contenido de la clase. De su actitud entusiasta, alegre y participativa dependerá el éxito del proceso de enseñanza-aprendizaje.

Como inicio el profesor deberá introducir el tema a tratar y comenzar su explicación. Para ello podrá apoyarse en herramientas tales como power point, prezi, Knovio, Powtoons y/o cualquier aplicación para la edición de animaciones gráficas (Ulead GIF Animator) o bien alguna para elaborar presentaciones que le permita exponer en forma práctica, animada e interactiva el contenido. También podrá apoyarse en la proyección de un video con una duración adecuada y/o alguna herramienta virtual de lectura.

La función del docente en esta etapa es convertirse en facilitador del aprendizaje, en constructor del acto didáctico en sí, a través de las diversas actividades que planifique ejecutar en el aula de clase.

3. Después de la clase: En este momento el docente debe iniciar el proceso de evaluación del aprendizaje. El Reglamento General a la Ley Orgánica de Educación Intercultural del Ecuador, en su artículo 184 define la evaluación estudiantil como un proceso continuo de observación, valoración y registro de información que evidencia el logro de objetivos de aprendizaje de los estudiantes, mediante sistemas de retroalimentación que están dirigidos a mejorar la metodología de enseñanza y los resultados de aprendizaje. (Reglamento LOEI, 2012, p.189). De acuerdo con esta premisa corresponde al docente en 
esta fase evaluar en los alumnos la comprensión del contenido expuesto utilizando estrategias didácticas que le permitan a su vez reforzar aquellos puntos aún no asimilados totalmente y aclarar las inquietudes que pudieran suscitarse.

En función a esto, el profesor deberá proceder a valorar el aprendizaje, preferiblemente a través de actividades valorativas prácticas: rompecabezas, mapas digitales, representaciones en grupo, etc. Esto le permitirá reforzar la clase, corregir deficiencias e interactuar con los alumnos.

Otra estrategia para el reforzamiento del aprendizaje es el trabajo cooperativo en grupo. Para ello el docente deberá servir de guía en la discusión y análisis de la temática; reforzar y aclarar el contenido; intervenir para propiciar el debate y realizar el cierre de la participación. Es recomendable que los grupos sean de pocos alumnos y escogidos de forma aleatoria con el propósito de lograr un intercambio de ideas enriquecedor.

Recursos necesarios: El docente deberá contar con recursos audiovisuales disponibles en el aula de clase tales como: proyector, pc o laptop con herramientas gráficas y multimedia.

\section{Consideraciones Finales}

Del estudio empírico se deduce que existen diferencias significativas entre los indicadores: formación docente, estrategias del aprendizaje, metodología del aprendizaje y ambiente en el aula; lo que permitió inferir la necesidad de capacitar al maestro en el uso de estrategias de animación interactiva para la enseñanza de los Estudios Sociales en el cuarto grado de Educación General Básica.

A partir de estos hallazgos se elaboró una propuesta metodológica fundamentada en el currículo ecuatoriano vigente que incluyó tres momentos de la clase: antes, durante y después; fases de planificación donde el docente puede definir las herramientas de animación interactiva a utilizar, aplicarlas y evaluarlas en función de cada contenido temático.

\section{Referencias Bibliográficas}

Ander, E (2011). Aprender a Investigar. Nociones Básicas para la investigación social. Primera Edición. Editorial Brujas. Argentina.

Arias, F (2012). El Proyecto de Investigación, introducción a la metodología científica, sexta (6) edición. Editorial Episteme. Venezuela

Asamblea Constituvente de la República del Ecuador. Reglamento general a la ley orgánica de educación intercultural. Quito, Ecuador. Recuperado el 15 7-2019, desde http://www.forosecuador.ec/forum/ecuador/educaci\%C3\%B3ny-ciencia/170802-pdf-loei-y-su-reglamento-2019-ley-org\%C3\%Alnica-deeducaci\%C3\%B3n-intercultural-ecuador

Belloch, C (s/f). Aplicaciones multimedia interactivas: Clasificación. Unidad de Tecnología Educativa. Universidad de Valencia. España. Recuperado el $15-$ 07-2019. Disponible en: https://www.uv.es/bellochc/pdf/pwtic3.pdf

Bolaño, M (2017). Uso de Herramientas Multimedia Interactivas en educación preescolar. Revista Didáctica, Innovación y Multimedia (DIM). Año 14 - No 35 mayo 2017 - ISSN: 1699-3748. España. Recuperado el 18-08-2019. Disponible en: https://ddd.uab.cat/pub/dim/dim_a2017m5n35/dim_a2017m5n35a4.pdf

Eguaras Alcántara, V (2015). Los 12 principios de la animación para el desarrollo de contenidos y fomento de las inteligencias múltiples en 4to. De educación plástica y visual. Trabajo de fin de master. Universidad Internacional de la Rioja. España.

García-Hernández, A (2014). Estrategia metodológica para la elaboración y utilización de objetos de aprendizaje interactivo y experimental en el proceso de enseñanza aprendizaje de la Matemática Discreta en la UCI. Tesis presentada en opción al título académico de Máster en Ciencias Matemáticas. La Habana, Cuba: Universidad de la Habana.DO.10.13140/RG.2.1.2189.1925

Hernández, R., Fernández, C y Baptista, P (2014) Metodología de la Investigación, 6a . Edición, McGraw Hill/Interamericana Editores S.A DE C.V., México

Hofstetter, F (2001). Multimedia Literacy 3rd McGraw-Hill, Inc. New York, NY, USA 1 ISBN: 0073659983. Disponible en: https://dl.acm.org/citation. cfm?id=540539

Horno, A (2011). Animación interactiva como metodología didáctica. Congreso internacional de innovación docente (pág. 1). Cartagena: Congreso internacional de innovación docente campus Mare Nostrum. Disponible en: http://repositorio. $\underline{\text { upct.es/bitstream/handle/10317/2351/p24.pdf? sequence }=1 \text { \&is Allowed }=\text { V }}$

Kajekai, R (2011) Estrategias y recursos didácticos para enseñar estudios sociales en el séptimo año de educación general básica en la escuela ETSAr del Centro Shuar Muchinkim, Parroquia de Tayuza. Periodo lectivo 20102011. Tesis de grado. Universidad Politécnica Salesiana, Sede Cuenca. Ecuador. Recuperado el: 1006-2019. Disponible en: https://dspace.ups.edu.ed bitstream/123456789/1405/13/UPS-CT002161.pdf

Laborí, B (s/f). Estrategias educativas para el uso de las nuevas tecnologías de la información y comunicación. Revista Iberoamericana de Educación, 1-13. Recuperado el 10-06-2019. Disponible en: www.rieoei.org > deloslectores > Labori

Ministerio de educación de la República de Ecuador (2016). El currículo de Ciencias Sociales de los niveles de educación obligatoria. Ecuador. Recuperado el 10-08-2019. Disponible en: https://educacion.gob.ec

Ministerio de educación de la República de Ecuador (2016) acuerdo Nro. MINEDUC-ME-2016-00020-A Reformado según acuerdo Nro. MINEDUCMINEDUC-2018-00089-A. Ecuador. Disponible en:_https://educacion.gob.ec

Quinquer, D (2004). Estrategias metodológicas para enseñar y aprender ciencias sociales: interacción, cooperación y participación. Íber 40, pp. 7-22. Recuperado el 10-08-2019. Disponible en: http://sutcobao.org.mx/pdf/comprimidos/ Estrategias\%20metodol\%C3\%B3gicas\%20para\%20ense\%C3\%Blar\%20y\%20 aprender $\% 20$ ciencias $\% 20$ sociales.pdf 


\section{Encuentros / ISSN 1692-5858}

Rodríguez, F (2015) Animación abstracta: técnica y estética de una corriente cinematográfica. Tesis doctoral para optar al título de doctor. Universidad de Vigo. España. Recuperado el 10-08-2019. Disponible en: http://www.investigo. biblioteca.uvigo.es/xmlui/bitstream/handle/1 1093/1002/Animacion_abstracta tecnica y estetica de una corriente cinematografica ligada al arte conceptual y de vanguardia.pdf? sequence $=1$

Sangra A., Guardia L., Mas X., Girona C. (2005) Los materiales de aprendizaje en contextos educativos virtuales. Pautas para el diseño tecno pedagógico. Colección educación y Sociedad Red. Editorial UOC. Barcelona - España. Recuperado el 12-04-2019. Disponible en: https://www.researchgate.net/ publication/299839886 Guardia_L_Sangra_A 2005 Diseno instruccional_y objetos de aprendizaje hacia un modelo para el diseno de actividades de evaluacion del aprendizaje online RED - Revista de Educacion a Distancia Monograf

Tavlor. R (2000). Enciclopedia de técnicas de animación. Editorial: Acanto editorial S. A.pp: 176

Tebar, L. (2003). El perfil del profesor mediador. Aula XXI. Santillana. Madrid. España. Recuperado el 12-04-2019. Disponible en: https://www.researchgate. net/publication/39698301 Tebar Belmonte_L 2003 El perfil del profesor mediador Aula XXI Santillana Madrid https://www.researchgate.net/ publication/39698301 Tebar Belmonte L 2003 El perfil del profesor mediador_Aula_XXI Santillana_Madrid

Tizón, G. (2008). Las TIC en educación. España. Editorial Lulupress. Inc. Disponible en: https://www.oei.es/historico/divulgacioncientifica/?DocentesEntornos-Multiconceptuales-TIC-Educandos-con-formacion-significativa

Thomas, F., y Johnston, O (1981). The illusion of life. Disney Animation. New York: Disney Edition Deluxe. Recuperado el 10-05-2019. Disponible en: https:// archive.org/stream/TheIllusionOfLifeDisneyAnimation/The\%20Illusion\%20 of\%20Life\%20Disney\%20Animation djvu.txt

UNESCO (1998). Declaración mundial sobre la educación superior en el siglo XXI: Visión y Acción. Recuperado el 11-06-2019. Disponible en: http:// www. unesco.org/education/educprog/wche/declaration_spa. html

Universidad de Murcia (2005). Tecnologías para los Sistemas Multimedia Curso 2004/05 - 1/23. Escuela de Informática. España. Recuperado el 11-062019. Disponible en: http://dis.um.es/ jfernand/0405/tsm/index.html 